Vietnam Academy of Science and Technology
Vietnam Journal of Earth Sciences
http://www.vjs.ac.vn/index.php/jse

\title{
Remote Sensing for Monitoring Surface Water Quality in the Vietnamese Mekong Delta: The Application for Estimating Chemical Oxygen Demand in River Reaches in Binh Dai, Ben Tre
}

\author{
Nguyen Thi Binh Phuong*1, Van Pham Dang Tri ${ }^{1}$, Nguyen Ba Duy ${ }^{2}$, Nguyen Chanh Nghiem ${ }^{1}$ \\ ${ }^{1}$ Can Tho University, Campus 2, Xuan Khanh Ward, Ninh Kieu Dist., Can Tho City, Vietnam \\ ${ }^{2}$ Mining and Geology University, Duc Thang ward, North Tu Liem dist., Ha Noi, Vietnam
}

Received 9 November 2016. Accepted 23 June 2017

\section{ABSTRACT}

Surface water resources played a fundamental role in sustainable development of agriculture and aquaculture. In this study, the approach of Artificial Neuron Network was used to estimate and detect spatial changes of the Chemical Oxygen Demand (COD) concentration on optical remote sensing imagery (Landsat 8). Monitoring surface water quality was one of the essential missions especially in the context of increasing freshwater demands and loads of wastewater fluxes. Recently, remote sensing technology has been widely applied in monitoring and mapping water quality at a regional scale, replacing traditional field-based approaches. The study used the Landsat 8 (OLI) imagery as a main data source for estimating the COD concentration in river reaches of the Binh Dai district, Ben Tre province, a downstream river network of the Vietnamese Mekong Delta. The results indicated the significant correlation $(\mathrm{R}=0.89)$ between the spectral reflectance values of Landsat 8 and the COD concentration by applying the Artificial Neuron Network approach. In short, the spatial distribution of the COD concentration was found slightly exceeded the national standard for irrigation according to the B1 column of QCVN 08:2015.

Keywords: Surface water quality, Chemical Oxygen Demand (COD), Landsat 8 (OLI), remote sensing, Artificial Neuron Network (ANN), Vietnamese Mekong Delta.

(C)2017 Vietnam Academy of Science and Technology

\section{Introduction}

Surface water quality monitoring was considered as one of the important techniques to achieve characteristics of surface water for supporting sustainable water resources man-

"Corresponding author, Email: ntbphuong19@gmail.com agement. Agriculture and aquaculture production is the major water consumption factors in the Vietnamese Mekong Delta (Ines et al., 2001). Expanding production area did not only contributes to a substantial increase in fresh water requirements but also to surface water pollution of the rivers (Renaud and Claudia, 2012). 
Nguyen Thi Binh Phuong, et al./Vietnam Journal of Earth Sciences 39 (2017)

Water quality monitoring has been studied by numerous researchers over the last several years. Many of them considered the optical parameters such as the total suspended sediment (TSS), chlorophyll-a (Chl-a) and turbidity indices (Lavery et al., 1993; Nas et al., 2010; Waxter, 2014). Some of the studies employed the statistical approaches to building the linear correlation while several studies focused on the Artificial Neuron Network (ANN) approach, a kind of nonlinear analytical technique. According to Chebud et al. (2012), the Artificial Neuron Network (ANN) could be used to monitor water quality via the application of the Landsat TM data; a significant relationship (R2) between the observed data and simulated water quality parameters was found greater than 0.95 (Imen et al., 2015). An empirical model was also developed to estimate the suspended sediment concentration due to intensive erosion processes by using the Landsat TM imagery in the Amazonian whitewater rivers (Montanher et al., 2014). By using the MOD09 and the Landsat TM 4-5 (TM) or Landsat 7 (ETM+) imagery, an early warning system for monitoring TSS concentrations was developed. It showed the high reliability of $\mathrm{R} 2$ value and root mean square between the observed and simulated TSS (0.98 and 0.5 respectively) (Imen et al., 2015). The research of Lim and Choi, (2015) demonstrated that the Landsat 8 OLI could be appropriate to monitor water quality parameters including suspended solids, total phosphorus, Chl-a and total nitrogen.

It was considered that the Chemical Oxygen Demand (COD) performed a weak optical characteristic leading to the low accurate estimation of COD by remote sensing technology (Gholizadeh et al., 2016). However, by using linear regression approach, the relatively good correlation between reflectance value retrieved from the Landsat TM images and ground data of COD reported by Wang et al., 2004 in reservoirs of Shenzen, Guangdong Province, China. It was shown that ANN approach could provide a better interpretation in comparison with what could be found via the linear approach (Sudheer et al., 2006; Wang et al., 1977). Chebud et al., 2012 applied the ANN model to monitor phosphorus, Chl-a and turbidity in Kissimmee River by using Landsat TM, their result of the square of significant correlation coefficient exceeds 0.95 was reported. The results also indicated that the root mean square error values for phosphorus, turbidity, and Chl-a were around $0.03 \mathrm{mg} \mathrm{L}-1$, $0.5 \mathrm{NTU}$, and $0.17 \mathrm{mg} \mathrm{m}-3$, respectively. According to $\mathrm{Wu}$ et al. (2014), ANN could predict TSS concentration better than the multiple regression $(\mathrm{MR})$ approach $(\mathrm{R} 2=0.66$ and 0.58 , respectively).

According to the traditional field-based approaches, COD was monitored locally by sampling water at monitoring sites where historical records of COD are available. Although this method showed its relatively acceptable accuracy at point level, it was still a huge challenge to analyze the COD concentration in a region in terms of substantial time, human resources consuming and financial supports for collecting a large sufficient information (Lim and Minha, 2015). However, regional monitoring could provide a general view of the distribution of pollutant concentration through mapping surface water quality as well as to support the policy-makers in giving recommendations for local residents. Remote sensing technology indicated its efficiency and helps in monitoring spatial distribution of water quality parameters (Bonansea et al., 2015; Yusop et al., 2011).

The aim of this study was to investigate the relationship between spectral reflectance value of the Landsat 8 and ground data of the COD concentration and to access spatial changes of such the parameter in river reaches of the Binh Dai district, Ben Tre province. The study also proposed an optical remote sensing approach based for mapping and monitoring the COD concentration in downstream river reaches of the Vietnamese Mekong Delta.

\section{Study river reaches}

The study river reaches locates in downstream of the Mekong River at the Binh Dai district, Ben Tre province (Figure 1). When the system flows through Binh Dai, it is 
divided into two main branches, namely Cua Dai and Ba Lai before draining into the East Sea. In the dry season, average flows of Cua Dai and Ba Lai River are about $1,598 \mathrm{~m}^{3} / \mathrm{s}$ and $60 \mathrm{~m}^{3} / \mathrm{s}$, respectively while they are approximately $6,480 \mathrm{~m}^{3} / \mathrm{s}$ and $350 \mathrm{~m}^{3} / \mathrm{s}$ respectively in the rainy season. These two rivers are the main water source for the agriculture and freshwater-based aquaculture purposes. Mekong River brings sediments that mainly contribute to form coastal area in Ben Tre. It is characterized by flat topography, attaining an average elevation of 1-2 meters above sea level (Nguyen et al., 2010; Le et al., 2014). The irregular semi-diurnal tide (two times of high and low tides per day) affects significantly on hydrological regime of the coastal area of Binh Dai. The tidal amplitude is about $2.5 \mathrm{~m}$ to $3.0 \mathrm{~m}$ in spring tide periods and approximately $1 \mathrm{~m}$ in neap tide periods (Le et al., 2014; PPC, 2016). It gives the huge impacts of the tidal regime and the COD concentration in the river change substantially in time and space.

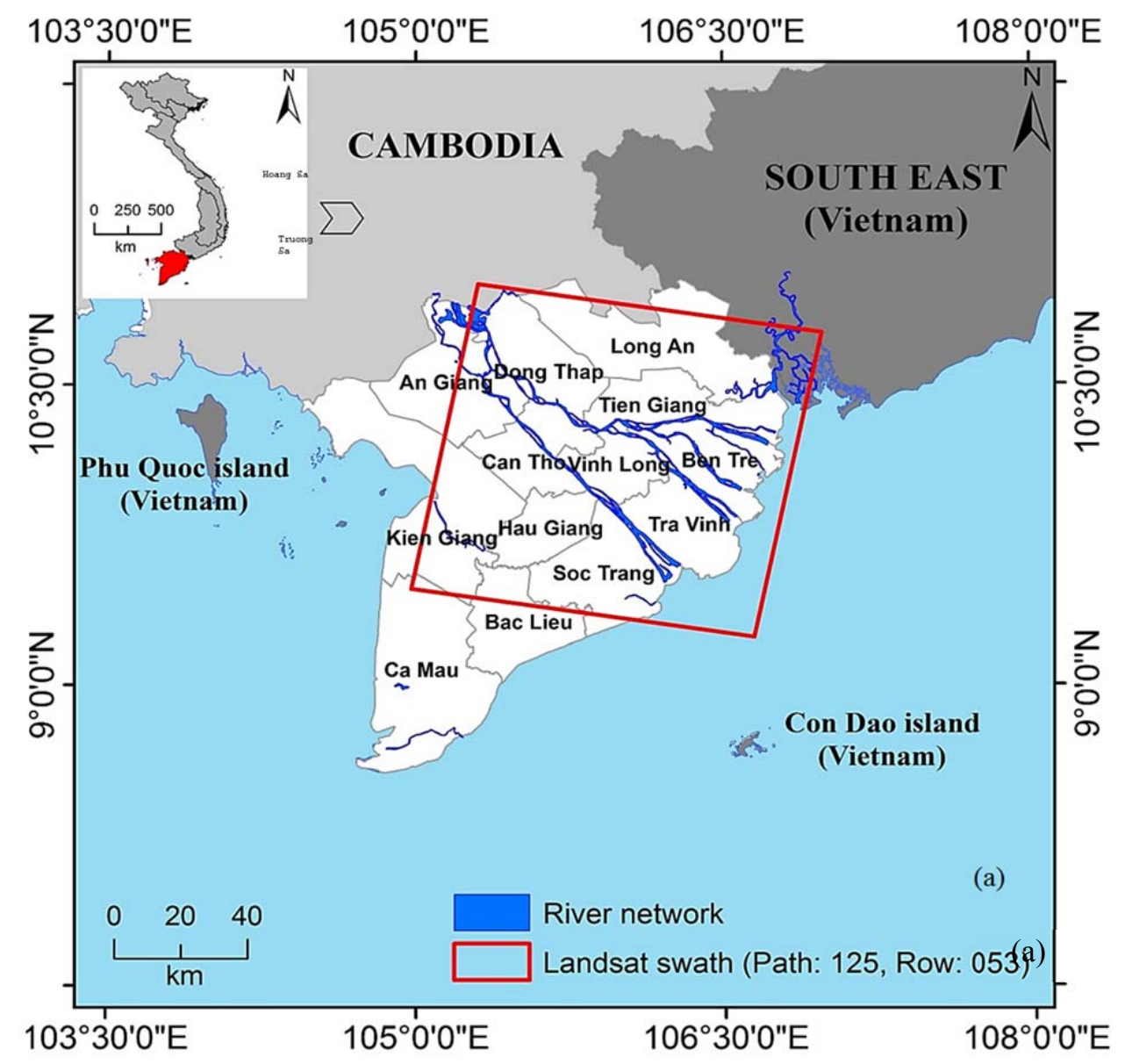

Figure 1. (a) Landsat swath of study area 


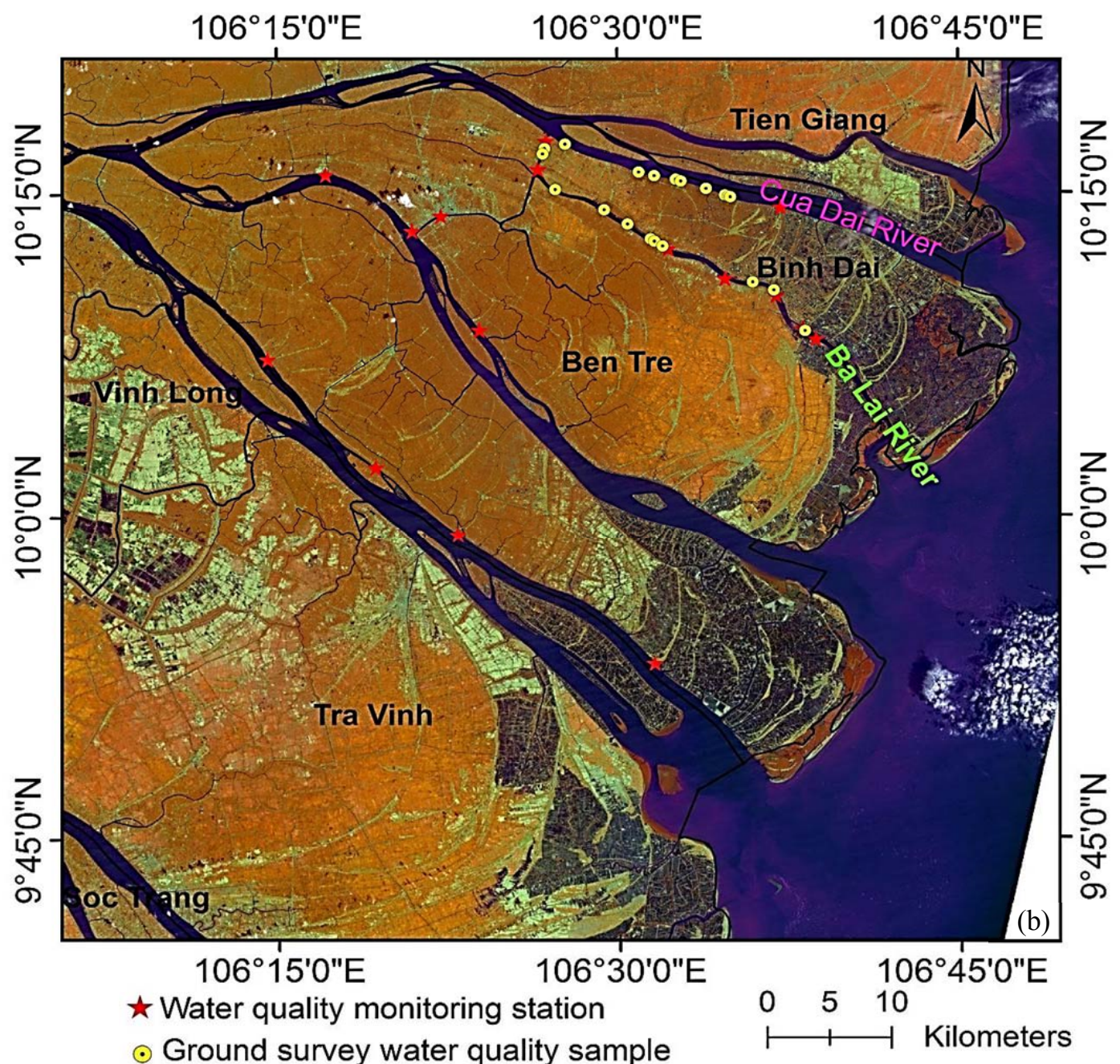

Figure 1. (b) water quality monitoring station and sample sites

\section{Methodology}

There are five main steps (Figure 2) for estimating the COD concentration which are: (i) collecting optical remote sensing data and ground-truth data, (ii) pre-processing available the Landsat-8 images (calibration and atmospheric correction and cloud detection); (iii) detecting riverbank and masking water related pixel; (iv) extracting reflectance values; and (v) developing the model for estimating spatial distribution of COD concentration.

\subsection{Optical remote sensing data and ground- truth data collection}

Optical remote sensing data were provided from the website Earth Resources Observation and Science Center (EROS), U.S Geological Survey http://glovis.usgs.gov/.

Table 1 indicates the information about the Landsat images collected at the at different time points. To extract the riverbank, two cloud-free scenes of the Landsat 7 and Landsat 
8 were collected on December 14, 2002, and September 18, 2014. Two scenes of the Landsat 8 (the least cloud cover) were collected on February 22, 2014, and January 24, 2015, and then were used to analyze COD concentration. To establish the correlation algorithms between spectral reflectance values and ground data, optical remote sensing data was collected on 27 January 2016 in the same day when water samples were collected at 10:11 am in 23 sites placed along the main axis of the Cua Dai and Ba Lai River (Figure 1). However, three samples were not able to be used because of the

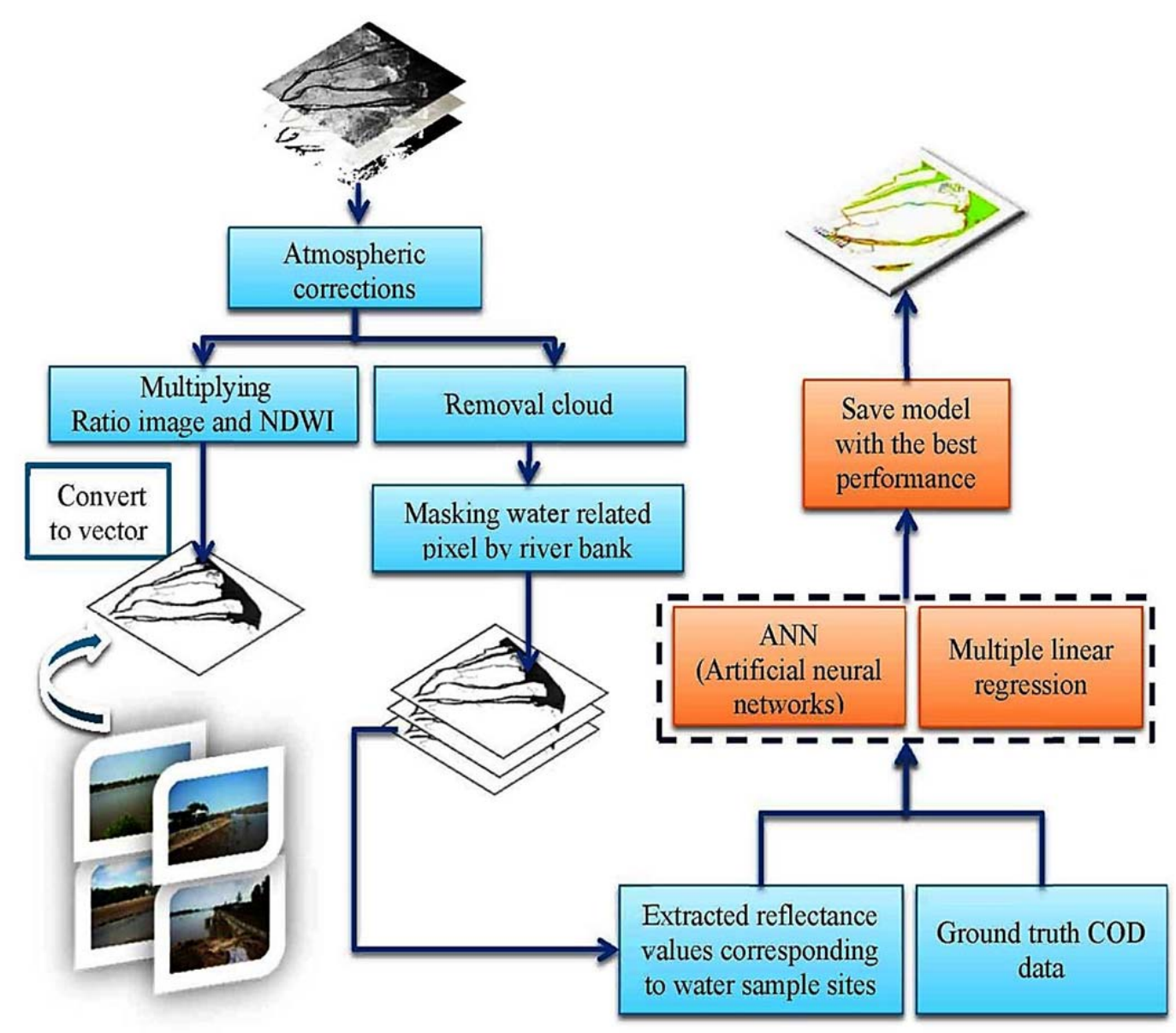

Figure 2. The framework for developing of the COD-estimation model 
Nguyen Thi Binh Phuong, et al./Vietnam Journal of Earth Sciences 39 (2017)

Table 1. The information on the collected Landsat images

\begin{tabular}{|c|c|c|c|c|}
\hline Sl.No & Date & Landsat & Revolution (meters) & Band 1 \\
\hline 1 & December 14, 2002 & ETM & $30 \times 30$ & \\
\hline 2 & September 18, 2014 & OLI & $30 \times 30$ & \\
\hline 3 & January 24, 2015 & OLI & $30 \times 30$ & \\
\hline 4 & April 14, 2015 & OLI & $30 \times 30$ & \\
\hline 5 & January 27, 2016 & OLI & $30 \times 30$ & \\
\hline 6 & February 22, 2014 & OLI & $30 \times 30$ & \\
\hline
\end{tabular}

\subsection{Pre-processing Landsat 8 images}

\subsubsection{Atmospheric correction}

The COST model developed by Chávez (1996) was applied to correct for effects of the atmosphere. It converts digital number (DN) values to into the Top-of-Atmosphere (TOA) radiance. Moreover, by using information from the metadata file, TOA reflectance was converted into ground reflectance values. 


\subsubsection{Cloud detection}

In this research, The Fmask package (version 3.2) was used to detect clouds and cloud shadows in the Landsat 8 images. In version 3.2, the new Short Wave Infrared (band 9, Landsat 8) that is useful for detecting high altitude clouds was applied instead of the band 7 (Landsat 7) in the original version (Ackerman et al., 2010, Zhu and Woodcock, 2012). The TOA reflectance value of the band 9 was used to compute a cirrus cloud probability. The different kind of clouds is able to be detected by applying the old cloud probability and new cirrus cloud probability. The cirrus cloud probability is directly proportional to the TOA reflectance of the cirrus band. If the cirrus band TOA reflectance equals 0.04 , the cirrus cloud probability equals 1 (Zhu et al., 2015).

\subsection{Riverbank extraction and masking water related pixel}

Riverbank area was defined as a barrier between land and water was affected by human activities as well as natural process (Alesheikh et al., 2007). It was necessary for extracting water pixel to identify the shape of riverbank as well as river system (Pham and Nguyen Duc Anh, 2011). Two scenes of the Landsat 7 and Landsat 8 in study River Reaches were collected in 2003 and 2014 with the very low percentage of cloud cover. The atmospheric correction process was conducted using the COST model that indicated the accuracy of correction algorithms. The contrast between the land and water was highlighted from Alesheikh's research to meet to South Vietnam condition (Casse et al., 2012). Then, the shape of a river was digitized by using convert vector tool in QGIS. Two layers of riverbank extracted from the Landsat 7 (2003) and Landsat 8 (2014) were used to overlap identifying changes of the riverbank. Based on these results, fieldwork was conducted in several areas indicated the changes of the riverbank. This aims to reevaluate the results from Alesheikh's research applying to the coastal area. The results of fieldwork fairly meet the results of riverbank extraction from analyzing the satellite scenes. The layer of river bank extracted from the Landsat 8 (2014) was used to mask water related pixel by a masking tool in ENVI.

\subsection{Reflectance values extraction}

In the fieldwork, the coordination of water sample sites and stations was achieved. After images of the Landsat 8 were preprocessed, they were employed for retrieving surface reflectance values corresponding with geographical monitoring sites.

\subsection{Developing the model for estimating spa- tial distribution of $C O D$ concentration}

3.5.1. The multiple linear regression approach

The Pearson's correlation displays the linear relationship between 2 variables as follow:

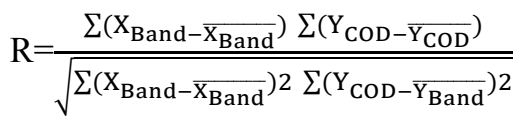

Where $X_{B a n d}$ is the reflectance value, $\mathrm{Y}_{\mathrm{COD}}$ is COD value in monitoring site, $\overline{\mathrm{X}_{\mathrm{Band}}}$ is mean of the reflectance value, $\overline{\mathrm{Y}_{\mathrm{COD}}}$ is mean of COD value in monitoring site

The multiple linear regression approaches performs the relationship between two or more explanatory variables and a response variable by establishing a linear equation as follow:

$$
\mathrm{Y}=\beta 0+\beta 1 \mathrm{X}_{\mathrm{Band} 1}+\beta 2 \mathrm{X}_{\mathrm{Band} 2}+\ldots+\beta \rho
$$

Where $Y$ is estimated COD, $\beta 0$ is intercept, $\beta 1, \beta 2, \beta \rho$ are regression coefficients

According to Wang et al. (2004), the higher correlation coefficient of 0.626 was found between COD concentration and reflectance values of band 1-3 of the Landsat 7 by multiple linear regression approaches in compari- 
son with linear, exponential and log transformations. In order to replace the Landsat 7 with the corresponding wavelengths, reflectance values band 2-4 of the Landsat 8 were employed as an alternative to reflectance values of the Landsat TM of band 1-3.

\subsubsection{The Artificial Neural Network approach}

Previous studies have shown that ANN could improve the accuracy of estimating water quality parameters as compared to traditional approaches (Sudheer et al., 2006; Chebud et al., 2012; Gholizadeh et al., 2016). Artificial neural networks can capture complex non-linear relationships between an input and output (Pham et al., 2015; Tien Bui et al., 2016). In this research, the structure of ANNs obtained three layers of interconnected neurons, called input layer, hidden layer and the

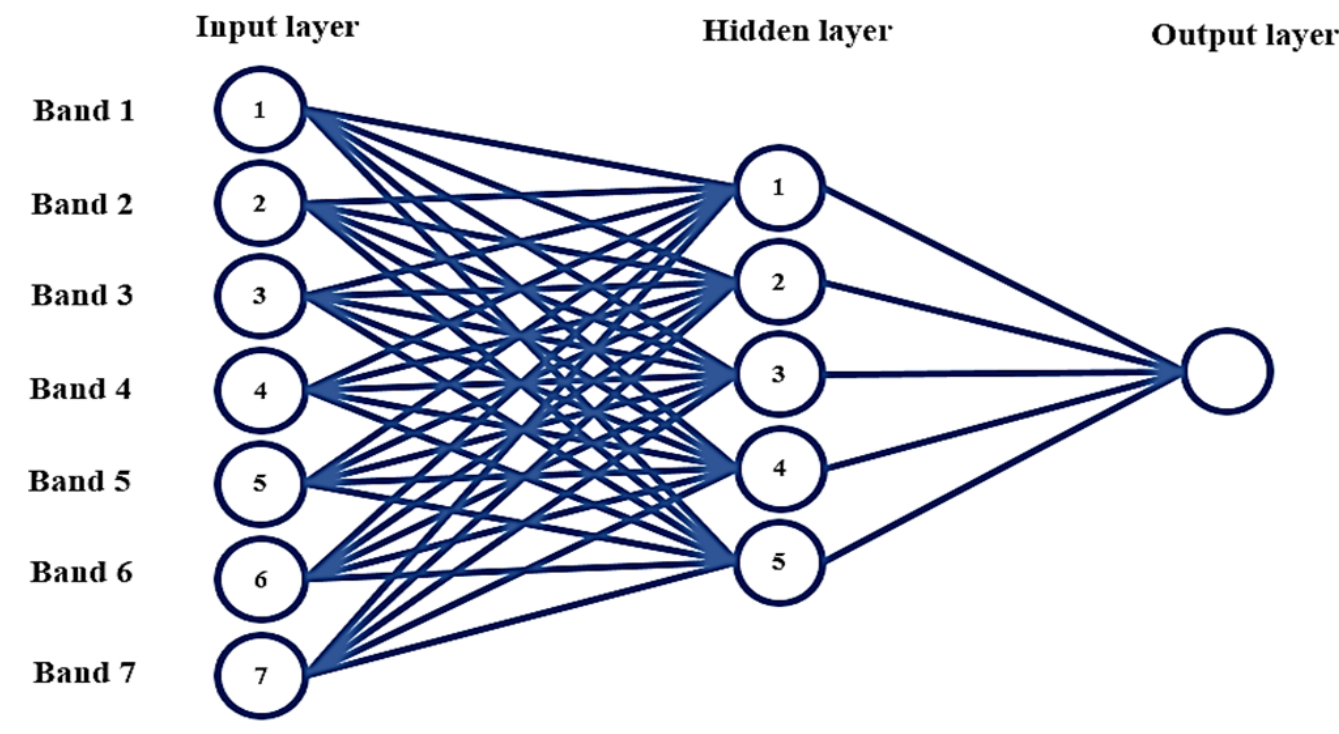

Figure 3. Structure of ANN with three layers

$$
\mathrm{C}=\alpha E_{D}+\beta E_{w}
$$

Where $E_{D}$ is the sum of squared errors, $E_{w}$ is the sum of squared weights, $\alpha$ and $\beta$ are called hyperparameters lows: output layer (Figure 3). According to Kaur and Salaria (2013), Bayesian Regularization showed the best performance of function estimation with the capability of overcoming/avoiding the over-fitting problem when training the network in effort estimation with obtaining the ability to process over-fitting during ANN training. Therefore, Bayesian Regularization was applied to update the weight and bias values according to Levenberg-Marquardt optimization. It minimizes a combination of squared errors and weights and then determines the correct combination so as to produce a network that generalizes well. According to Tien Bui et al. (2012), in order to calculate the distance between real data and detected data, Bayesian Regularization employed a common function as follows:

Hidden layer Output layer 
over, Gauss-Newton approximation can be applied to Hessian matrix.

$$
\begin{aligned}
& \alpha=\frac{\Upsilon}{2 E_{w}} \\
& \beta=\frac{n-\Upsilon}{2 E_{w}} \\
& \Upsilon=N-\alpha \operatorname{trace}(H)^{-1}
\end{aligned}
$$

Where $\Upsilon$ is number of effective parameters; $\mathrm{H}$ is Hessian matrix of objective function $\mathrm{S}(\mathrm{w}) ; \mathrm{N}$ is the total number of parameters in the network.

(4) Iterate steps 2 to 3 until convergence.

To solve the over-fitting problem, the data was divided into two datasets with $70 \%$ of the dataset for training and $30 \%$ of the dataset for testing in the network (Imen et al., 2015). In this research, a standard feed-forward network with one hidden layer was employed. There were five neurons in the hidden layer. The inputs to the networks were a combination of the reflectance values from the bands of the Landsat 8 corresponding with geographical monitoring sites. The measured COD concentration values with the corresponding geo-

graphical sites were used as targets. There was a single neuron that indicated the detected COD in output player. A number of 14 network models with different inputs were trained to determine the best combinations of the reflectance values of the Landsat- 8 bands. The neural network was trained 50 times for each model. The performance of each network was evaluated by the root mean square error (RMSE) and the correlation coefficient (R) (Were et al., 2015).

\section{Results and Discussion}

\subsection{COD concentration from water samples}

Figure 4 indicated COD concentration of 35 sites located along the main axis of Cua Dai and Ba Lai River. For 20 water samples collected on 27 January 2016, COD concentration exceeds the standard B1 column of QCVN 08: 2015 in several points. COD concentration exceeding the standard B2 column of QCVN 08: 2015 was found in 2 water samples of Cua Dai River.

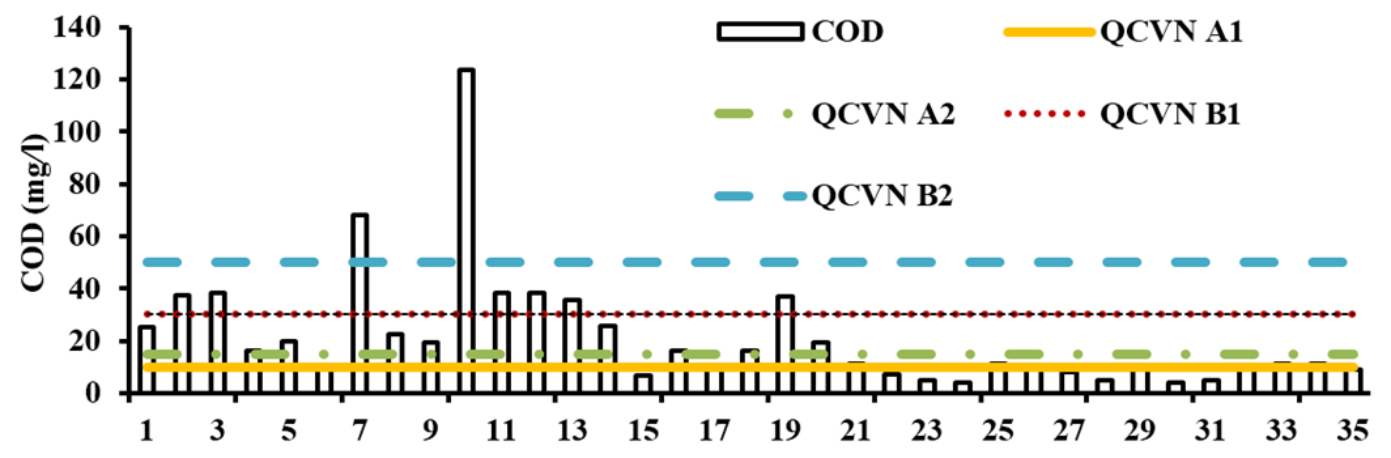

Figure 4. COD concentration from collected water samples and the national standard according to the A1, A2, B1, B2 column of QCVN 08: 2015

\subsection{The COD-estimation model}

In order to investigate the relationship between COD and reflectance values of Landsat 8 , the research employed the multiple linear regression and ANN approach.

\subsection{The multiple linear regression approach}

Table 2 indicates the Pearson's correlation analysis the individual bands of the Landsat 8 and COD concentration. It is evidenced from the Table 2 that there are weak negative linear relationships between reflectance values of individual bands of the Landsat 8 and COD concentration, ranging from -0.50 to -0.11 . Reflectance values of band 3 performed the highest correlation with $\operatorname{COD}(\mathrm{R}=-0.49)$ while reflectance values of band 5 performed the lowest correlation with $\operatorname{COD}(\mathrm{R}=-0.11)$. 
Nguyen Thi Binh Phuong, et al./Vietnam Journal of Earth Sciences 39 (2017)

The defective sensor resulted in missing data in the Landsat 7 images that can lead to errors in the extracted maps. Therefore, in this research, the Landsat 8 was used to replace the Landsat 7. However, there is a difference in the spectral bandwidth between the Landsat 8 and the Landsat 7 (Table 2). To keep corresponding wavelengths, reflectance values of band 2-4 of the Landsat 8 were used to replace reflectance values of Landsat TM of band 1-3. The multiple linear regression between the reflectance values of band 2-4 of the Landsat 8 and COD values showed that there was a weak correlation of $\mathrm{R}=-0.53$ and RMSE $=4.50$ through this approach although its correlation coefficient was higher than correlation coefficient of reflectance values of individual bands and COD concentration.

Table 2. Correlation of the Landsat 8 bands and COD

\begin{tabular}{cccccccc}
\hline Index & B1 & B2 & B3 & B4 & B5 & B6 & B7 \\
\hline COD & -0.3 & -0.42 & -0.49 & -0.38 & -0.11 & -0.27 & -0.12 \\
\hline
\end{tabular}

\subsection{Artificial Neural Network}

The performance of the networks is presented by the correlation coefficient and the root mean square in Table 3 after they were trained using Bayesian regulation. Comparing the correlation coefficients of the networks using only the reflectance value of a single band as input, it is obvious that network M2, M3, and M4 have the higher correlation coefficients for both training and testing. The M3 displayed highest $\mathrm{R}$ for training, test and all, having $0.87,0.76$ and 0.86 respectively while there was an insignificant relationship between M5 and observed COD concentration. Although B2, B3 and B4 combination (M9) correlated significantly with $\mathrm{COD}$ concentration $(\mathrm{R}=0.87)$, the combination of $\mathrm{B} 1, \mathrm{~B} 2, \mathrm{~B} 3$ and B4 (M10) showed the highest correlation coefficient $(\mathrm{R}=0.89)$. These results demonstrated that COD estimation using ANN was more accurate than the linear regression approach.

\subsection{Assessing the COD concentration in 2014 and 2015}

The research focused on two scenes of the Landsat 8 with the low percentage of cloud cover (Figure 5, Figure 6).

Table 3. Performance of the COD concentration in ANN

\begin{tabular}{|c|c|c|c|c|c|c|c|}
\hline \multirow{2}{*}{ Model } & \multirow{2}{*}{ Input band } & \multicolumn{2}{|c|}{ Training } & \multicolumn{2}{|c|}{ Test } & \multicolumn{2}{|c|}{ Training and Testing } \\
\hline & & $\mathrm{R}$ & RMSE & $\mathrm{R}$ & RMSE & $\mathrm{R}$ & RMSE \\
\hline M1 & $\mathrm{B} 1$ & 0.26 & 15.15 & 0.50 & 10.66 & 0.30 & 13.90 \\
\hline M2 & B2 & 0.81 & 13.01 & 0.55 & 7.00 & 0.79 & 11.46 \\
\hline M3 & B3 & 0.87 & 23.78 & 0.76 & 9.49 & 0.86 & 20.40 \\
\hline M4 & B4 & 0.39 & 24.26 & 0.50 & 15.54 & 0.42 & 21.90 \\
\hline M5 & B5 & 0.13 & 24.02 & 0.13 & 18.28 & 0.11 & 22.38 \\
\hline M6 & B6 & 0.34 & 10.82 & 0.49 & 11.96 & 0.30 & 11.19 \\
\hline M7 & B7 & 0.45 & 9.16 & 0.59 & 37.15 & 0.34 & 22.16 \\
\hline M8 & B3, B4 & 0.91 & 10.52 & 0.78 & 13.20 & 0.87 & 11.43 \\
\hline M9 & B2, B3, B4 & 0.92 & 10.15 & 0.80 & 11.57 & 0.87 & 10.62 \\
\hline M10 & B1, B2, B3, B4 & 0.92 & 9.35 & 0.82 & 21.43 & 0.89 & 14.29 \\
\hline M11 & $\mathrm{B} 1, \mathrm{~B} 2, \mathrm{~B} 3, \mathrm{~B} 4, \mathrm{~B} 5, \mathrm{~B} 6$ & 0.93 & 25.03 & 0.79 & 10.72 & 0.82 & 21.58 \\
\hline M12 & $\mathrm{B} 2, \mathrm{~B} 3, \mathrm{~B} 4, \mathrm{~B} 5, \mathrm{~B} 7$ & 0.66 & 19.65 & 0.75 & 15.39 & 0.60 & 18.41 \\
\hline M13 & $\mathrm{B} 1, \mathrm{~B} 2, \mathrm{~B} 3, \mathrm{~B} 4, \mathrm{~B} 5$ & 0.99 & 4.21 & 0.54 & 14.94 & 0.92 & 9.07 \\
\hline M14 & $\mathrm{B} 1, \mathrm{~B} 2, \mathrm{~B} 3, \mathrm{~B} 4, \mathrm{~B} 5, \mathrm{~B} 6, \mathrm{~B} 7$ & 0.71 & 17.60 & 0.77 & 13.52 & 0.72 & 16.42 \\
\hline
\end{tabular}




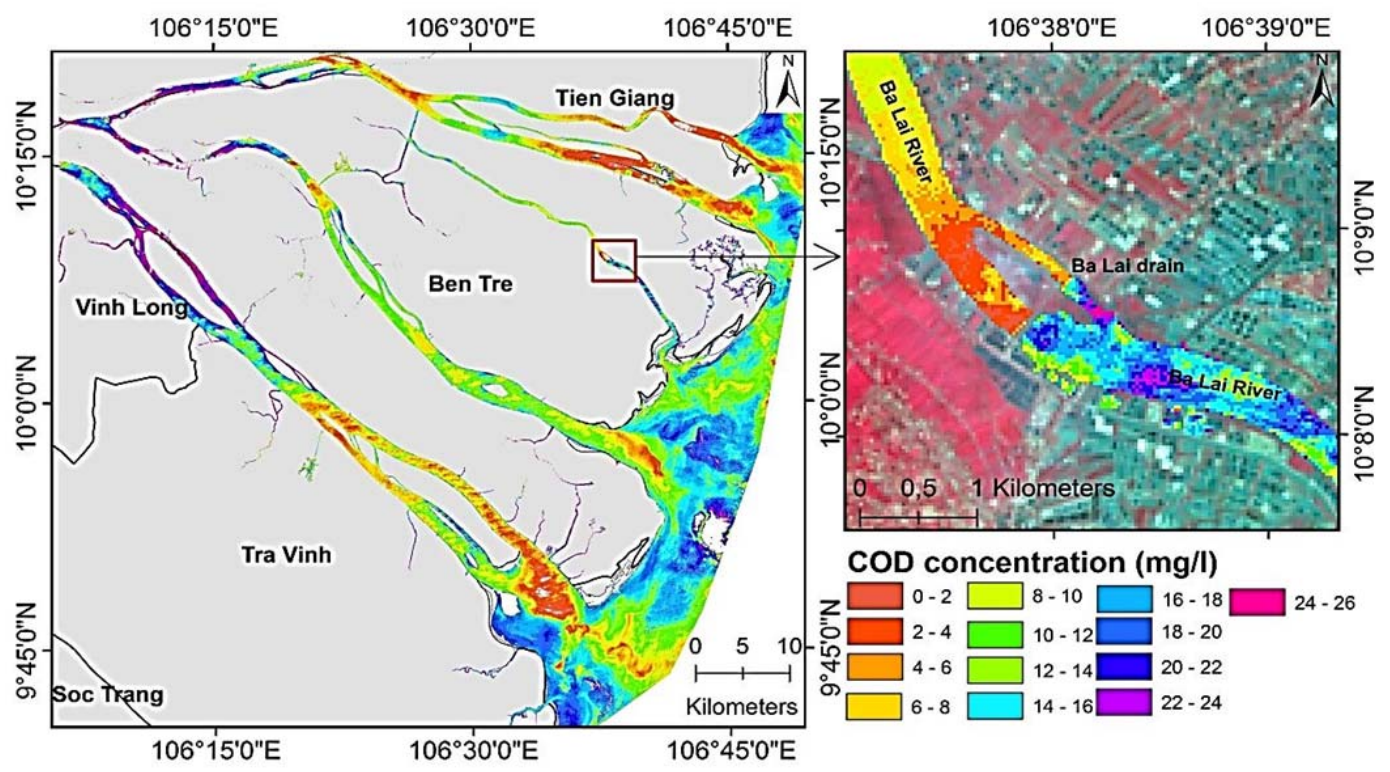

Figure 5. Estimated COD concentration map on February 22, 2014 in Binh Dai

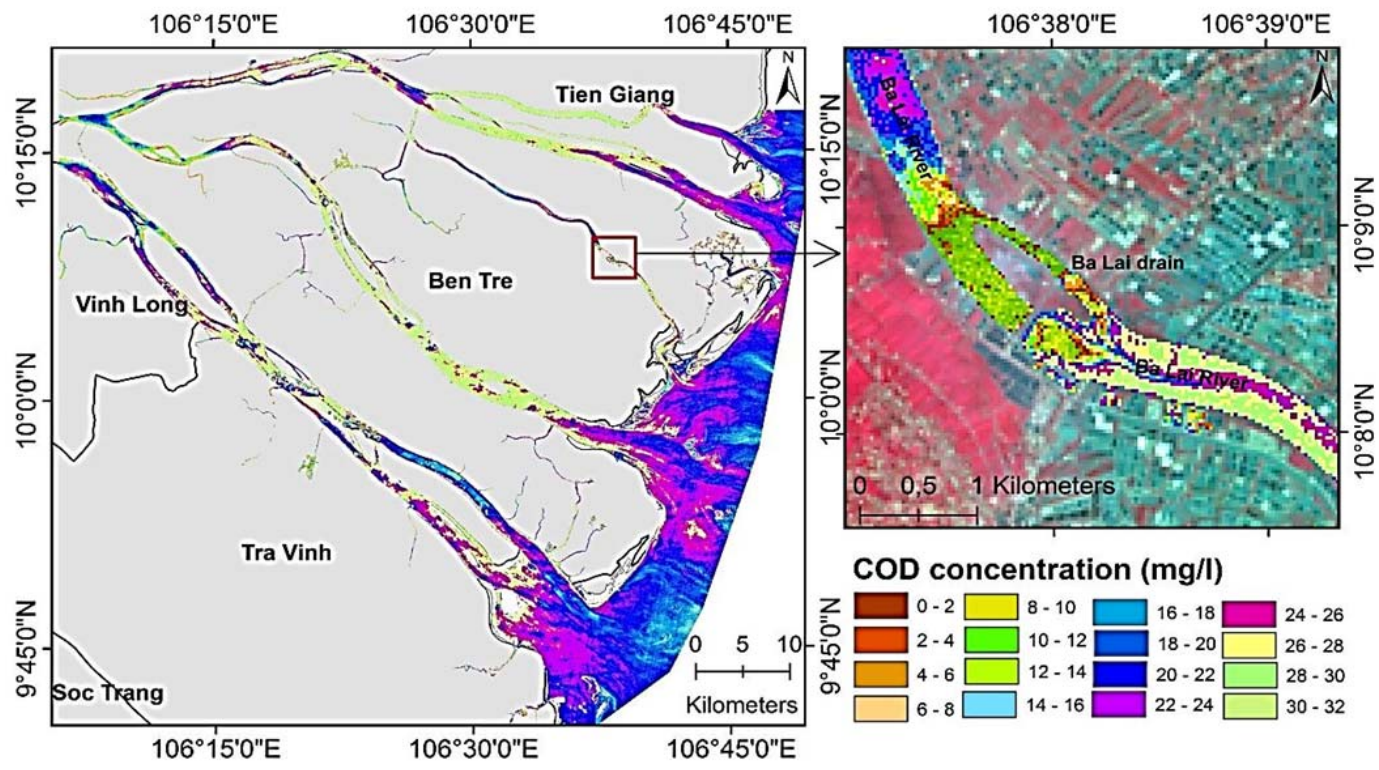

Figure 6. Estimated COD concentration map on January 24, 2015 in Binh Dai

Hydrological regime of Ba Lai River is affected by sluice gate systems while Cua Dai river has no control by construction irrigation systems. The operation schedule of Ba Lai sluice is one of the reasons caused a considerable distribution of COD concentration in surface water in Ba Lai River. On February 22, 2014, it was evidenced that COD concentra- 
Nguyen Thi Binh Phuong, et al./Vietnam Journal of Earth Sciences 39 (2017)

tion inside $\mathrm{Ba}$ Lai sluice was low, ranging from 1 to $10 \mathrm{mg} / \mathrm{l}$ in comparison with COD concentration outside $\mathrm{Ba}$ Lai sluice, ranging from 5 to $21 \mathrm{mg} / \mathrm{l}$ (Figure 5). The map also dedicated COD concentration reduced gradually from Ba Lai sluice to the estuary. On January 24,2015 , there was a fluctuation from 22 $\mathrm{mg} / \mathrm{l}$ to approximately $30 \mathrm{mg} / \mathrm{l}$ in the river section between Ba Lai sluice and the estuary although several sites were found that the COD concentration exceeded slightly the national standard for irrigation according to the B1 column of QCVN 08:2015 (Figure 6). Aquaculture activities are the major likelihood of resident in the coastal area with increasing annual production area, one of the main sources of pollutant in this area. The distribution of high COD concentration was also found on a section of Cua Dai river, from Tam Hiep to Thoi Trung Island, ranging from 25 to $31 \mathrm{mg} / 1$. In several sites of this section, COD concentration exceeded slightly the national standard of $30 \mathrm{mg} / 1$ shown in B1 column of QCVN 08: 2015.

\section{Conclusions}

Landsat 8 provided the potential of optical remote sensing data source for estimating a large spatial distribution of the COD concentration, which was almost impossible via a traditional field-based approach. However, there was a limitation in monitoring the temporal distribution of the COD concentration due to local weather conditions of the coastal area, significantly reducing the quality of satellite data.

The ANN approach provided better COD estimation than traditional regression model. Experimental results also showed that the combination of reflectance values of bands 1 to 4 of Landsat 8 were the most appropriate inputs to the applied model.

It should be noted that it is difficult and time-consuming to determine the optimal architecture of the neural network that could generalize well without over-fitting the data. In addition, quantifying the uncertainty in the network outputs should be considered, especially in cases of relatively small training data set.

\section{Acknowledgments}

We would like to express greatly our appreciation to The Kurita Water and Environment Foundation Grant funded for this study.

\section{References}

Ackerman S., Richard F., Kathleen S., Yinghui L., Chris M., Liam G., Bryan B., and Paul M., 2010. Discriminating clear-sky from cloud with MODIS algorithm theoretical basis document (MOD35).

Ali Sheikh A.A., Ghorbanali A., and Nouri N., 2007. Coastline change detection using remote sensing. International Journal of Environmental Science and Technology 4(1), 61-66.

Bonansea M., María C.R., Lucio P., and Susana F., 2015. Using multi-temporal Landsat imagery and linear mixed models for assessing water quality parameters in Río Tercero reservoir (Argentina). Remote Sensing of Environment 158, 28-41. Available at http://linkinghub.elsevier.com/retrieve/pii/S0034425 714004544.

Casse C., Viet P.B., Nhung P.T.N., Phung H.P., and Nguyen L.D., 2012. Remote sensing application for coastline detection in Ca Mau, Mekong Delta. Proceeding of International Conference on Geometics for spatial Infrastructure development in Earth and Allied Science-GIS IDEAS.

Chávez P.S., 1996. Image-based atmospheric corrections-revisited and improved. Photogrammetric engineering and remote sensing, 62(9), 1025-1035.

Chebud Y., Ghinwa M.N., Rosanna G.R., and Assefa M.M., 2012. Water Quality Monitoring Using Remote Sensing and an Artificial Neural Network. Water Air \& Soil Pollution 223(8), 4875-4887. Available at http://link.springer.com/10.1007/s11270-0121243-0.

Gholizadeh M.H., Assefa M.M., and Lakshmi R., 2016. A Comprehensive Review on Water Quality Parameters Estimation Using Remote Sensing Techniques. 
Vietnam Journal of Earth Sciences, 39(3), 256-269

Sensors (Basel, Switzerland) 16(8), 1298. Available at http://www.mdpi.com/1424-8220/16/8/1298/htm.

Imen S., Ni-Bin C., and Y.J.Y., 2015. Developing the remote sensing-based early warning system for monitoring TSS concentrations in Lake Mead. Journal of Environmental Management 160, 73, 89. Available at http://linkinghub.elsevier.com/retrieve/pii/S0301479 715300943.

Ines A.V.M., Peter D., Ian W.M., and Ashim G. D., 2001. Crop Growth and Soil Water Balance Water Modeling to Explore Water Management Water Options. Colombo.

Kaur H., and Dalwinder S.S., 2013. Bayesian Regularization Based Neural Network Tool for Software Effort Estimation. Global Journal of Computer Science and Technology Neural \& Artificial Intelligence 13(2), 44-50. Available at https:/globaljournals.org/GJCST_Volume13/6Bayesian-Regularization-Based-Neural.pdf.

Lavery P., Charitha P., Alex W., and Peter H., 1993. Water quality monitoring in estuarine waters using the Landsat thematic mapper. Remote Sensing of Environment 46(3), 268-280.

Le A.T., Du L.V., and Tristan S., 2014. Rapid integrated and ecosystem-based assessment of climate change vulnerability and adaptation for Ben Tre Province, Viet Nam. Journal of Science and Technology 52(3A), 287-293.

Lim J. and Minha C., 2015. Assessment of water quality based on Landsat 8 operational land imager associated with human activities in Korea. Environmental monitoring and assessment 187(6), 4616. Available at http://www.scopus.com/inward/record.url?eid=2s2.0-84930209268\&partnerID=tZOtx3y1.

Montanher O.C., Evlyn M.L.M.N., Claudio C.F.B., Camilo D.R., and Thiago S.F.S., 2014. Empirical models for estimating the suspended sediment concentration in Amazonian white water rivers using Landsat 5/TM. International Journal of Applied Earth Observation and Geoinformation 29(1), 67-77. Available at http://dx.doi.org/10.1016/j.jag.2014.01.001.

Nas B., Semih E., Hakan K., Ali B., and David J.M., 2010. An application of landsat-5TM image data for water quality mapping in Lake Beysehir, Turkey. Water Air and Soil Pollution 212(1-4), 183-197.
Nguyen D.D., Lam D.D., Ha V. Van, Tan N.T., Tuan D.M., Quang N.M., and Cuc N.T.T., 2010. New stratigraphic unit - The Early Holocene Binh Dai formation at the estuary and coastal area of Cuu Long delta. Vietnam Journal of Earth Sciences 32, 335-342.

Pham B.T., Dieu T.B., Hamid R.P., Prakash I., and Dholakia M.B., 2015. Landslide susceptibility assesssment in the Uttarakhand area (India) using GIS: a comparison study of prediction capability of naïve bayes, multilayer perceptron neural networks, and functional trees methods. Theoretical and Applied Climatology 128(1-2), 255-273.

Pham Q.S. and Anh N.D., 2011. Evolution of the coastal erosion and accretion in the Hai Hau district (Nam Dinh province) and neighboring region over the last 100 years based on topographic maps and multitemporal remote sensing data analysis. Vietnam Journal of Earth Sciences 311(2002), 82-85.

PPC, 2016. Environmental Impacts Assessment (BSWAMP). Ben Tre.

Renaud F.G. and Claudia K., 2012. The Mekong Delta System: Interdisciplinary Analyses of a River Delta (FG Renaud and C Kuenzer, Eds.). Springer Dordrecht Heidelberg New York London.

Sudheer K.P., Indrajeet C., and Vijay G., 2006. Lake water quality assessment from landsat thematic mapper data using neural network: An approach to optimal band combination selection. Journal of the American Water Resources Association 42(6), 1683-1695.

Tien Bui D., Pradha B., Owe L., Inge R., and Oystein B.D., 2012. Landslide susceptibility assessment in the Hoa Binh province of Vietnam: A comparison of the Levenberg-Marquardt and Bayesian regularized neural networks. Geomorphology 171-172, 12-29Available at http://dx.doi.org/10.1016/j.geomorph.2012.04.023.

Tien Bui D., Tuan T.A., Harald K., Biswajeet P., and Inge R., 2016. Spatial prediction models for shallow landslide hazards: a comparative assessment of the efficacy of support vector machines, artificial neural networks, kernel logistic regression, and logistic model tree. Landslides 13(2), 361-378.

Wang Y., Hao X., Jiamo F., and Guoying S., 2004. Water quality change in reservoirs of Shenzhen, China: Detection using LANDSAT/TM data. Science of The 
Nguyen Thi Binh Phuong, et al./Vietnam Journal of Earth Sciences 39 (2017)

Total Environment 328(1-3), 195-206. Available at http://linkinghub.elsevier.com/retrieve/pii/S0048969 704001007.

Wang J.P., Cheng S.T., and Jia H.F., 1977. Application of Artificial Neural Network Technology in Water Color Remote Sensing Inversion of Inland Water Body Using Tm Data.

Waxter M.T., 2014. Analysis of Landsat Satellite Data to Monitor Water Quality Parameters in Tenmile Lake, Oregon.

Were K., Dieu T.B., Øystein B.D., and Bal R.S., 2015. A comparative assessment of support vector regression, artificial neural networks, and random forests for predicting and mapping soil organic carbon stocks across an Afromontane landscape. Ecological Indicators 52: 394-403. Available at http://dx.doi.org/10.1016/j.ecolind.2014.12.028.

Wu J.L., Chung-Ru H., Chia-Ching H., Arun L.S.,
Jing-Hua T., and Yao-Tung L., 2014. Hyperspectral sensing for turbid water quality monitoring in freshwater rivers: Empirical relationship between reflectance and turbidity and total solids. Sensors (Switzerland) 14(12), 22670-22688.

Yusop S.M., Abdullah K., Lim H.S., and Md N.A.B., 2011. Monitoring water quality from Landsat TM imagery in Penang, Malaysia. Proceeding of the 2011 IEEE International Conference on Space Science and Communication (IconSpace), 249-253.

Zhu Z. and Curtis E.W., 2012. Object-based cloud and cloud shadow detection in Landsat imagery. Remote Sensing of Environment 118, 83-94.

Zhu Z. Shixiong W., and Curtis E.W., 2015. Improvement and expansion of the Fmask algorithm: Cloud, cloud shadow, and snow detection for Landsats 4-7, 8, and Sentinel 2 images. Remote Sensing of Environment 159, 269-277. 